\title{
Indicadores de comportamento para auxiliar o entendimento de discussões online
}

\author{
Lívia C Gouvêa ${ }^{1}$, Ana Cristina B Garcia ${ }^{1}$, Adriana S Vivacqua ${ }^{2}$ \\ ${ }^{1}$ Departamento de Sistemas de Informação - Universidade Federal do Estado do Rio de Janeiro \\ ${ }^{2}$ Departamento de Ciência da Computação - Universidade Federal do Rio de Janeiro \\ \{livia.faria,cristina.bicharra\}@uniriotec.br, avivacqua@dcc.ufrj.br
}

\section{Resumo}

Ambientes de colaboração online têm mudado radicalmente a forma como o conhecimento é criado e gerenciado pela sociedade. A facilidade de uso, o baixo custo, o amplo alcance e a liberdade de expressão têm proporcionado a mobilização e agregação de comunidades abertas e auto-organizáveis. No entanto, deliberações nestes ambientes mostram-se muitas vezes volumosas dispersas e redundantes, não havendo facilidade de convergência de opiniões para apoiar decisões. Ao mesmo tempos os usuários tendem a se reunir em grupos que compartilham a mesma opinião (balcanização) não havendo assim a troca de pontos de vista divergentes [Klein 2012]. Estes ambientes muito homogêneos também contribuem para que usuários assumam posições extremas sobre questões polêmicas, fenômeno conhecido como polarização. Além disso, à medida que a discussão se desenvolve, a compreensão da discussão pode se tornar cada vez mais difícil para os recém-chegados, e esse problema tende a aumentar conforme o grupo cresce [Garcia and Klein 2015] pois os usuários tendem a levantar uma ampla gama de subtópicos relacionados ao tópico temático sobre o qual estão discutindo [Zhang and Setty 2016]. Estas evidências sugerem que, embora as ferramentas e ambientes de colaboração online sejam poderosas em apoiar a criação e difusão novos conteúdos, sua capacidade de promover um debate justo e transparente é questionável.

Alguns trabalhos já foram realizados com o objetivo de contornar estes problemas em ambientes de deliberação online. A utilização de mapas argumentativos onde as contribuições são construídas em uma estrutura de árvore foi utilizada para facilitar a organização do conteúdo e evitar redundâncias. A classificação dos tópicos de discussão foi utilizada para exibir tópicos implícitos, escondidos pelo estilo conversacional dos fóruns [Zhang and Setty 2016] e sumarização de tópicos foi proposta para auxiliar usuários a se aprofundarem na discussão e não somente ler os comentários mais bem ranqueados que ficam em destaque [Ren et al. 2011]. A eficácia da mineração de dados foi destacada como forma de auxiliar a identificação de características de comportamentos em redes sociais [Chen et al. 2017] e a análise de sentimentos e nuvem de palavras geradas a partir os dados do debate foram utilizadas para apoiar facilitadores a gerenciar discussões em larga escala [Ito et al. 2018].

A partir da identificação do problema e revisão das soluções existentes, observamos que não exitem trabalhos sugerindo a sumarização do debate aliada à identificação da dinâmica de comportamento dos usuários como forma de auxiliar o entendimento da discussão. Por isso, o presente trabalho se propõe a expor identificadores de comportamento sobre a dinâmica da discussão aliados à sumarização da mesma como forma de auxiliar 
novos usuários a entrar em deliberações que já estejam em curso. Propomos apresentar ao novo usuário uma descrição do debate contendo informações básicas, tais como: número de participantes, data de início do debate, número de posts até o momento, tamanho médio das postagens, frequência média de posts por dia e média de postagens por participante. O modelo (apresentado na Figura 1) fornecerá também informações sobre a dinâmica de interação dos participantes, como: dominância de falantes (identificação de participantes que postam muito mais que os outros), dominância de post (identificação de postagens que foram muito mais respondidas do que as demais), grau de controvérsia (indicação de quão quente é o debate baseado nos votos positivos e negativos dados aos comentários), existência de groupthinking (identificação de postagens que respondem a postagens com mais votos positivos), existência de polarização e balcanização (identificação de grupos a partir de clusterização) e dinâmica temporal (identificação de intensidade do debate baseado na quantidade de posts diários). A próxima etapa desta pesquisa será a execução de um experimento para confirmar se o entendimento de novos usuários sobre uma discussão aumenta com a apresentação de sumarização aliada à indicadores de comportamento da discussão.

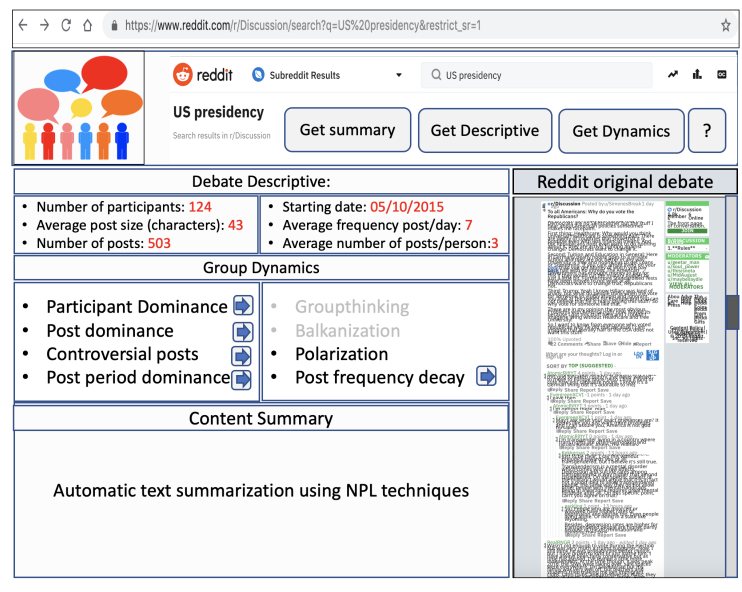

Figure 1. Interface do modelo

\section{References}

Chen, S., Lin, L., and Yuan, X. (2017). Social media visual analytics. In Computer Graphics Forum, volume 36, pages 563-587. Wiley Online Library.

Garcia, A. C. B. and Klein, M. (2015). Making sense of large-group discussions using rhetorically structured text.

Ito, T., Imi, Y., Ito, T., and Hideshima, E. (2018). Collagree: Facilitator-mediated largescale consensus support system.

Klein, M. (2012). Enabling large-scale deliberation using attention-mediation metrics. Computer Supported Cooperative Work (CSCW), 21(4-5):449-473.

Ren, Z., Ma, J., Wang, S., and Liu, Y. (2011). Summarizing web forum threads based on a latent topic propagation process. pages 879-884.

Zhang, H. and Setty, V. (2016). Finding diverse needles in a haystack of comments: Social media exploration for news. In Proceedings of the 8th ACM Conference on Web Science, WebSci '16, pages 286-290, New York, NY, USA. ACM. 